\title{
Neurogranin: A Potential Biomarker of Neurological and Mental Diseases
}

\author{
Yang Xiang ${ }^{1,2+}$, Jiayan Xin ${ }^{3,2 t}$, Weidong Le ${ }^{1}$ and Yongjian Yang ${ }^{4 *}$ \\ 1 Institute of Neuroscience, Sichuan Academy of Medical Sciences and Sichuan Provincial People's Hospital, School \\ of Clinical Medicine, University of Electronic Science and Technology of China, Chengdu, China, ${ }^{2}$ Department of Neurology, \\ General Hospital of Western Theater Command, Chengdu, China, ${ }^{3}$ North Sichuan Medical College, Nanchong, China, \\ ${ }^{4}$ Department of Cardiovasology, General Hospital of Western Theater Command, Chengdu, China
}

OPEN ACCESS

Edited by:

Mark Stecker,

Independent Practitioner, Fresno,

United States

Reviewed by:

Guangming Zhu,

Stanford University, United States

Yanxing Chen,

Zhejiang University, China

*Correspondence:

Yongjian Yang

yangyj86570999@sina.com

tThese authors have contributed equally to this work

Received: 18 July 2020

Accepted: 02 September 2020

Published: 06 October 2020

Citation:

Xiang Y, Xin J, Le W and Yang Y (2020) Neurogranin: A Potential Biomarker of Neurological and Mental

Diseases.

Front. Aging Neurosci. 12:584743.

doi: 10.3389/fnagi.2020.584743
Neurogranin $(\mathrm{Ng})$ is a small protein usually expressed in granule-like structures in pyramidal cells of the hippocampus and cortex. However, its clinical value is not fully clear so far. Currently, $\mathrm{Ng}$ is proved to be involved in synaptic plasticity, synaptic regeneration, and long-term potentiation mediated by the calcium- and calmodulin-signaling pathways. Due to both the synaptic integrity and function as the growing concerns in the pathogenesis of a wide variety of neurological and mental diseases, a series of researches published focused on the associations between $\mathrm{Ng}$ and these kinds of diseases in the past decade. Therefore, in this review, we highlight several diseases, which include, but are not limited to, Alzheimer's disease, Parkinson disease, Creutzfeldt-Jakob disease, neuro-HIV, neurosyphilis, schizophrenia, depression, traumatic brain injury, and acute ischemic stroke, and summarize the associations between cerebrospinal fluid or blood-derived $\mathrm{Ng}$ with these diseases. We propose that $\mathrm{Ng}$ is a potential and promising biomarker to improve the diagnosis, prognosis, and severity evaluation of these diseases in the future.

Keywords: neurodegenerative disorder, mental disorder, biomarker, cerebrospinal fluid, neurogranin

\section{INTRODUCTION}

Neurogranin (Ng, also called RC3, p17, and BICKS) is a protein with a molecular weight of $7.5 \mathrm{kD}$ and composed of 78 amino acids (Watson et al., 1990). It is often found in granule-like structures in pyramidal cells of the hippocampus and cortex, which gives rise to its name of "neurogranin" (Represa et al., 1990). Ng was discovered in 1990; however, its clinical value is not fully clear so far.

The mammalian Ng gene NRGN spans around $12.5 \mathrm{kbp}$ and contains four exons and three introns (Martinez de Arrieta et al., 1997). The human Ng sequence predicts five amino acids encoded by exon 1 and 73 amino acids encoded by exon 2 (Martinez de Arrieta et al., 1997). However, the other two exons contain untranslated sequences (Martinez de Arrieta et al., 1997). The coding sequence homology of NRGN between humans and rats is $90 \%$ at the nucleic acid level and $96 \%$ at the protein level (Martinez de Arrieta et al., 1997). In early studies, Ng was found principally as a neuronal postsynaptic protein in the telencephalon of the adult rat, specifically

Abbreviations: $\mathrm{AD}$, Alzheimer's disease; $\mathrm{AIS}$, acute ischemic stroke; $\mathrm{A} \beta$, amyloid $\beta$; $\mathrm{BACE1}$, precursor protein cleaving enzyme; CCI, controlled cortical impact; CJD, Creutzfeldt-Jakob disease; CNS, central nervous system; CSF, cerebrospinal fluid; DLB, dementia with Lewy bodies; FTD, frontotemporal dementia; GPI, general paresis of the insane; HD, Huntington disease; $\mathrm{MCI}$, mild cognitive impairment; NDEs, neuronal-derived exosomes; NDs, neurodegenerative disorders; neuroHIV, neuro-human immunodeficiency virus; NfL, neurofilament light; Ng, neurogranin; NRGN, neurogranin gene; NS, neurosyphilis; PD, Parkinson disease; PDD, PD with dementia; p-tau, phosphorylated tau; ROC, receiver operating characteristic; TBI, traumatic brain injury; t-tau, total tau. 
located in the cell bodies and dendrites of neurons in the cerebral cortex, hippocampus, and striatum (Represa et al., 1990) (Figure 1). Thereafter, Ng was detected successively in the lung, spleen, and bone marrow with a low expression level (Diez-Guerra, 2010). Moreover, high and moderate levels of $\mathrm{Ng}$ were found in platelets and B type lymphocytes, respectively (Glynne et al., 2000; Gnatenko et al., 2003). A recent study first identified $\mathrm{Ng}$ expression in both human and mouse endothelia (Cheriyan et al., 2020).

The present data strongly point that $\mathrm{Ng}$ is involved in the plasticity and regeneration of synapse mediated by the calciumand calmodulin-signaling pathways. For instance, Zhong et al. (2009) found that $\mathrm{Ng}$ enhances the postsynaptic sensitivity an elevates the synaptic strength in an activity- and NMDARdependent manner (Zhong et al., 2009). Besides, the potentiation of synaptic transmission modulated by $\mathrm{Ng}$ mimics and occludes the long-term potentiation (Zhong et al., 2009). A recent study revealed that long-term blockade of NMDAR significantly decreases Ng expression (Garrido-Garcia et al., 2019). Moreover, the long-term bicuculline administration facilitates synaptic activity and increases Ng expression (Garrido-Garcia et al., 2019). Lentiviral expression of $\mathrm{Ng}$ results in the elevated density of both excitatory and inhibitory synapses (Garrido-Garcia et al., 2019). In addition, $\mathrm{Ng}$ is involved in a variety of biochemical processes and molecular interactions (Figure 2).

Of note, synaptic integrity and function are both the growing concerns in the pathogenesis of a wide variety of neurological and mental diseases (Fyfe, 2015; Hellwig et al., 2015; Yang et al., 2015; Zetterberg and Blennow, 2015; Bereczki et al., 2017; De Vos et al., 2017; Guha et al., 2018; Blennow et al., 2019). In animal experiments, it showed that mice lacking NRGN show a remarkable decline in hippocampus-dependent spatial memory and deficits in hippocampal long-term potentiation (Pak et al., 2000). Aging is associated with the cognitive decline as well as the decreased $\mathrm{Ng}$ levels in pyramidal neurons (Mons et al., 2001). Ng reduction and cognitive deficit detected in 5XFAD mice are restored after the intra-hippocampal injection with an $\mathrm{Ng}$ expressing lentiviral vector (Jeon et al., 2018). On the basis of these basic studies, a series of researches published in the past decade focused on the associations between $\mathrm{Ng}$ and these kinds of diseases, which include, but are not limited to, AD, PD, CJD, HIV, infection (neuro-HIV), NS, TBI, AIS, and schizophrenia.

Therefore, in this review, we highlight and summarize several neurological and mental diseases associated with $\mathrm{Ng}$ and propose that $\mathrm{Ng}$ is a potential and promising biomarker to improve the diagnosis, prognosis, and severity evaluation of these diseases in the future.

\section{ASSOCIATIONS BETWEEN NEUROGRANIN AND NEUROLOGICAL AND MENTAL DISEASES}

Using the keywords, including "neurogranin," "Ng," "RC3," and "BICKS," we searched the clinical research articles involved in $\mathrm{Ng}$ via PUBMED and categorized them as per the kind of disease.
An overview of the major clinical researches involved in $\mathrm{Ng}$ was currently published (Table 1).

\section{Cerebrospinal Fluid Neurogranin in Neurodegenerative Disorders}

Neurodegenerative disorders (NDs) are characterized by progressive dysfunction of neurons, glias, synapses, as well as the neural networks (Kovacs, 2016, 2017). A critical feature of NDs is the aggregation and deposition of variants of physiological proteins in the CNS (Kovacs, 2016, 2017). Both neurons and glias have the capacity to accumulate these pathological variants (Kovacs, 2016, 2017). NDs can be broadly classified by their clinical presentations, most of which are the disorders of movement, cognition, mentation, or behavior. A small portion of patients develop pure syndromes, but most patients show mixed clinical features (Dugger and Dickson, 2017). AD and PD are the two kinds of the most common NDs. The occurrence of these types of NDs is usually in middle or old age, and the incidence is elevated with an increasing life expectancy of the population. In general, the diagnostic gold criteria of diverse NDs are neuropathological evaluation at autopsy. In comparison, the detectable biomarkers in vivo are supposed to improve the diagnosis, stratification, and prognosis of patients (Kovacs, 2016).

\section{Cerebrospinal Fluid/Plasma Neurogranin in Alzheimer's Disease}

As the most common kind of dementing disease, $\mathrm{AD}$ is a relentlessly progressive and fatal disorder of CNS, which begins approximately $10-15$ years before the clinical manifestations (Rafii, 2016). Pathologically, AD is characterized by both certain hallmarks in the brain, including the extracellular plaques composed of $A \beta$ peptide and the intracellular neurofibrillary tangles composed of the hyperphosphorylated tau protein (Blennow et al., 2006). Undoubtedly, the core CSF biomarkers of $\mathrm{A} \beta$ reflecting brain amyloidosis, $\mathrm{t}$-tau reflecting neurodegeneration intensity, and p-tau that is related to tau pathology, have good diagnostic accuracy in clinical practice. However, in view of the multifactorial pathogenesis of $\mathrm{AD}$ and the overlapping pathology with other kinds of dementia, it is necessary to integrate the core CSF biomarkers with other novel biomarkers that are capable of reflecting different aspects of neuropathology. Synaptic degeneration is an essential component of AD pathophysiology, which is present in early disease stages (Masliah et al., 2001; Scheff et al., 2007). An increasing amount of data suggests that synaptic dysfunction is associated with cognitive decline and ahead of neuronal degeneration (DeKosky and Scheff, 1990). Thus, the biomarkers reflecting the integrity and plasticity of synapses may be useful for the early diagnosis and prognosis of AD.

Many of clinical studies support the findings that the levels of CSF Ng are higher in AD or MCI patients than those in healthy controls (HCs) or non-AD dementia patients (Fyfe, 2015; Hellwig et al., 2015; Kester et al., 2015; Portelius et al., 2015). Higher levels of CSF $\mathrm{Ng}$ are positively correlated to higher scores of $\mathrm{A} \beta$ neuritic plaques and tau tangles pathology (Portelius et al., 2018). High levels of CSF Ng in AD and prodromal AD have 


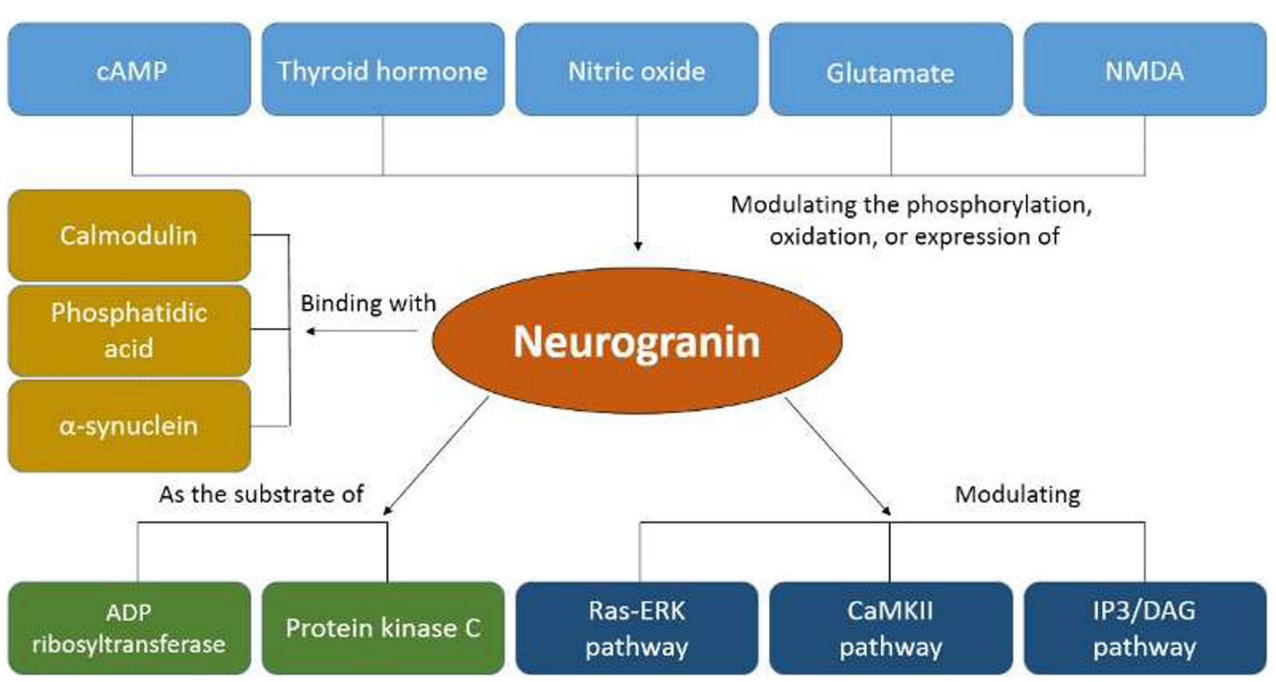

FIGURE 1 | Cellular and regional distribution of neurogranin in the adult rat brain.

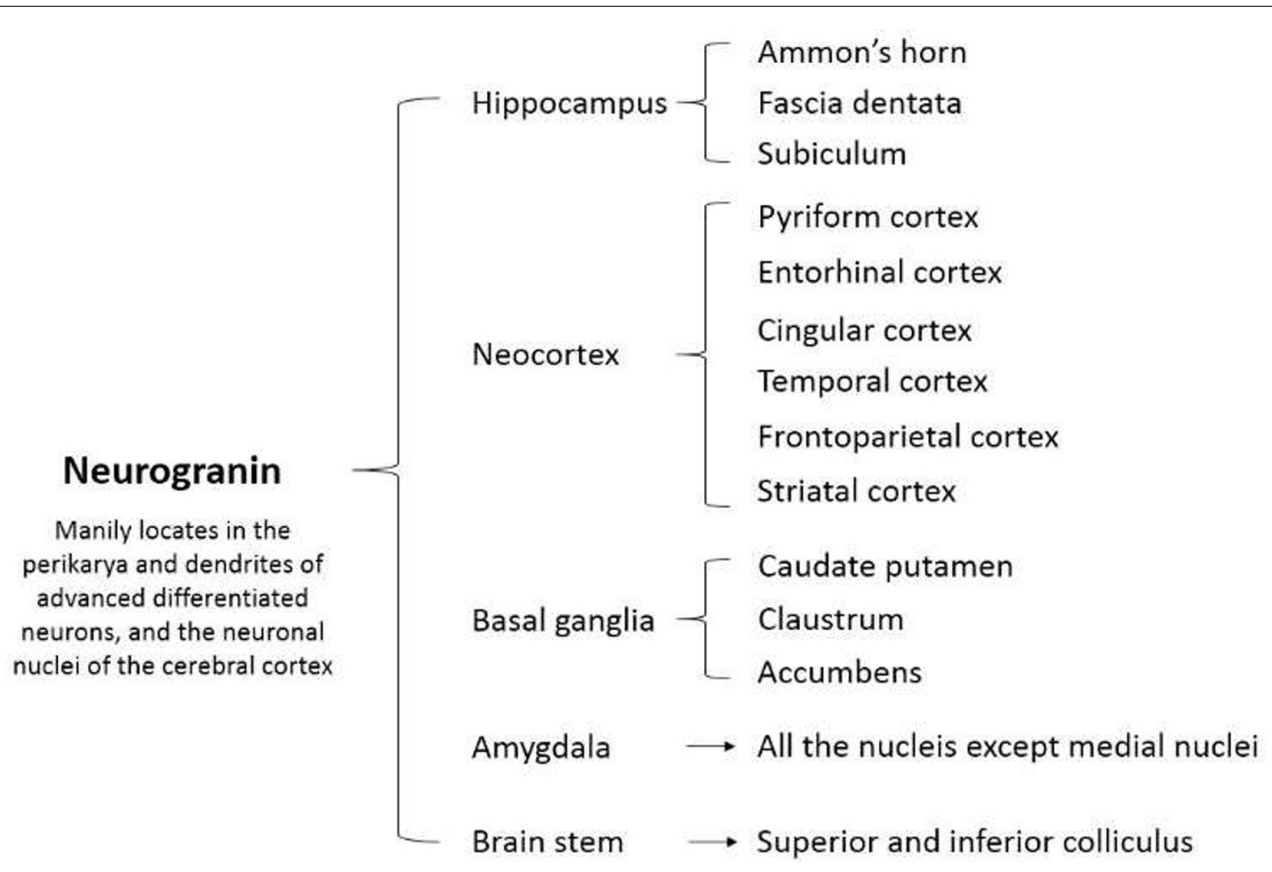

FIGURE 2 | A diagram of the molecular and signaling pathways involved in neurogranin. CAMP, cyclic adenosine monophosphate; NMDA, N-methyl-D-aspartate; ADP, adenosine diphosphate; ERK, extracellular signal-regulated kinase; CaMK II, calmodulin-dependent protein kinase II; IP3, inositol 1,4,5-trisphosphate; DAG, diacylglycerol.

been verified in several subsequent studies (Hellwig et al., 2015; Kvartsberg et al., 2015a).

A study explored the correlations between baseline CSF $\mathrm{Ng}$ levels with baseline and longitudinal cognitive decline, brain atrophy, and glucose metabolism (Portelius et al., 2015). They found that high baseline levels of CSF $\mathrm{Ng}$ in the MCI patients are associated with the longitudinal decline of hippocampal volume and cortical glucose metabolism at clinical follow-up (Portelius et al., 2015). Further, within the progressive
MCI group, elevated CSF Ng levels correlate with accelerated deterioration in Alzheimer's disease Assessment Scale-cognitive subscale (Portelius et al., 2015). In a recent meta-analysis, it revealed that the CSF $\mathrm{Ng}$ level is significantly higher in MCI patients progressed to $\mathrm{AD}$ than that in stable $\mathrm{MCI}$ patients (Mavroudis et al., 2019).

A cross-sectional and longitudinal observational study of cognitive decline between the symptomatic $\mathrm{AD}$ patients and cognitively normal controls proved that the CSF levels of $\mathrm{Ng}$ can 
TABLE 1 | An overview of the major clinical researches involved in $\mathrm{Ng}$ published currently.

\begin{tabular}{|c|c|c|c|c|c|c|}
\hline & Participants & Measures & Outcomes & Correlations & Study design & References \\
\hline \multirow[t]{9}{*}{$A D$} & $\begin{array}{l}\mathrm{ADD}(n=39) \mathrm{MCl}-\mathrm{AD} \\
(n=13) \mathrm{MCl}-\mathrm{o}(n=29) \\
\text { Non-ADD }(n=14)\end{array}$ & CSF Ng & $\begin{array}{l}\mathrm{MCl}-\mathrm{AD} \uparrow \text { vs. } \mathrm{MCl}-\mathrm{o} \\
\mathrm{ADD} \uparrow \text { vs. } \mathrm{MCl}-\mathrm{O}\end{array}$ & $\begin{array}{l}\text { Positively correlated } \\
\text { with CSF tau and p-tau. }\end{array}$ & $\begin{array}{l}\text { Case-control } \\
\text { study }\end{array}$ & $\begin{array}{l}\text { Hellwig et al., } \\
2015 ; \\
\text { Kvartsberg } \\
\text { et al., 2015b }\end{array}$ \\
\hline & $\begin{array}{l}\mathrm{AD}(n=65) \mathrm{MCl} \\
(n=61) \mathrm{CTRL}(n=37)\end{array}$ & $\mathrm{CSF} \mathrm{Ng}$ & $\begin{array}{l}\text { Baseline CSF levels of } \\
\mathrm{Ng}: \mathrm{AD} \uparrow \text { vs. CTRL } \\
\mathrm{MCl}-\mathrm{AD} \uparrow \text { vs. SMCl } \\
\text { Predicting progression } \\
\text { from } \mathrm{MCl} \text { to } \mathrm{AD}\end{array}$ & $\begin{array}{l}\text { Positively correlated } \\
\text { with CSF T-tau and } \\
\text { P-181 tau, but not with } \\
\text { A } 342 \text {. }\end{array}$ & $\begin{array}{l}\text { Longitudinal } \\
\text { study }\end{array}$ & $\begin{array}{l}\text { Kester et al., } \\
\text { 2015; } \\
\text { Zetterberg and } \\
\text { Blennow, } 2015\end{array}$ \\
\hline & $\begin{array}{l}\mathrm{ADD}(n=95) \mathrm{MCl} \\
(n=173) \mathrm{CTRL} \\
(n=110)\end{array}$ & CSF Ng & $\begin{array}{l}\mathrm{ADD} \uparrow \text { vs. } \mathrm{CTRL} \\
\mathrm{MCl} \uparrow \text { vs. CTRL } \\
\mathrm{sMCl} \uparrow \text { vs. CTRL } \\
\mathrm{pMCl} \uparrow \text { vs. CTRL } \\
\mathrm{pMCl} \uparrow \text { vs. SMCl }\end{array}$ & $\begin{array}{l}\text { High baseline CSF Ng } \\
\text { predicting cognitive } \\
\text { decline as reflected by } \\
\text { decreased MMSE. }\end{array}$ & $\begin{array}{l}\text { Case-control } \\
\text { study }\end{array}$ & $\begin{array}{l}\text { Portelius et al., } \\
2015\end{array}$ \\
\hline & $\begin{array}{l}\operatorname{ADD}(n=397) \mathrm{MCl} \\
(n=114) \mathrm{FTD}(n=96) \\
\operatorname{PDD}(n=29) \mathrm{DLB} \\
(n=33) \mathrm{CTRL}(n=75)\end{array}$ & $\begin{array}{l}\text { CSF Ng and } \\
\text { autopsy for the } \\
\text { neuropathology }\end{array}$ & $\begin{array}{l}\mathrm{ADD} \uparrow \text { vs. } \mathrm{CTRL} \\
\mathrm{ADD} \uparrow \text { vs. } \mathrm{MCl} \mathrm{AD} \\
\text { biomarker-positive } \\
\mathrm{CTRL} \text { subjects } \uparrow \text { vs. } \\
\text { AD biomarker negative } \\
\mathrm{CTRL} \text { group ADD vs. } \\
\mathrm{PD} \downarrow / \mathrm{PD} \mathrm{MCl} \downarrow / \mathrm{PDD} \downarrow \\
\mathrm{ADD} \uparrow \text { vs. FTD/ALS }\end{array}$ & $\begin{array}{l}\text { Positively associated } \\
\text { with: } A \beta \text { neuritic plaque } \\
\text { and tau tangle } \\
\text { pathology scores. }\end{array}$ & $\begin{array}{l}\text { Prospective } \\
\text { study }\end{array}$ & $\begin{array}{l}\text { Portelius et al., } \\
2018\end{array}$ \\
\hline & $\begin{array}{l}\operatorname{ADD}(n=100) \mathrm{MCl} \\
(n=40) \mathrm{CTRL}(n=80)\end{array}$ & CSF Ng & $\begin{array}{l}\text { Both } \mathrm{AD} \text { and } \mathrm{MCl}-\mathrm{AD} \text { : } \\
\text { markedly decrease; } \\
\text { The highest level in } \\
\text { ADD; High CSF } \mathrm{Ng} \\
\text { levels at the } \mathrm{MCl} \text { stage; } \\
\text { Predicting progression } \\
\text { to ADD. }\end{array}$ & $\begin{array}{l}\text { Positively correlated } \\
\text { with t-tau and } p \text {-tau, } \\
\text { but no correlations with } \\
\text { A } \beta \text { 1-42. }\end{array}$ & $\begin{array}{l}\text { Case-control } \\
\text { study }\end{array}$ & $\begin{array}{l}\text { Kvartsberg } \\
\text { et al., } 2015 a\end{array}$ \\
\hline & $\begin{array}{l}\mathrm{AD}(n=95) \mathrm{CTRL} \\
(n=207)\end{array}$ & CSF Ng & $\begin{array}{l}\text { The mean (SE) AUC } \\
\text { was } 0.73(0.04) \text { for } \mathrm{Ng} \\
\text { to differentiate patients } \\
\text { with early symptomatic } \\
\text { AD from CTRL; } \\
\text { Predicting future } \\
\text { cognitive impairment } \\
\text { (adjusted hazard ratio, } \\
\text { 1.89). }\end{array}$ & $\begin{array}{l}\text { CSF Ng level correlates } \\
\text { with a whole brain and } \\
\text { regional atrophy in } A D \text {, } \\
\text { and the amyloid load in } \\
\text { preclinical AD. }\end{array}$ & $\begin{array}{l}\text { Cross- } \\
\text { sectional and } \\
\text { longitudinal } \\
\text { observational } \\
\text { study }\end{array}$ & $\begin{array}{l}\text { Tarawneh et al., } \\
2016\end{array}$ \\
\hline & $\begin{array}{l}\mathrm{AD}(n=10) \mathrm{MCl} \\
(n=20) \mathrm{MCl}-\mathrm{AD} \\
(n=20) \operatorname{CTRL}(n=10)\end{array}$ & $\begin{array}{l}\text { Plasma NDEs } \\
\text { levels of: } \\
\text { PT-181-tau } \\
\text { PS-396-tau A } \beta \\
1-42 \mathrm{Ng}\end{array}$ & $\begin{array}{l}\text { AD/MCI vs. CTRL: } \\
\text { Plasma NDE levels of } \\
\text { PT-181-tau } \\
\text { PS-396-tau, and Abeta } \\
1-42 \uparrow \text { Plasma NDE } \\
\text { levels of Ng } \downarrow\end{array}$ & $\mathrm{N} / \mathrm{A}$ & $\begin{array}{l}\text { Case-control } \\
\text { study }\end{array}$ & $\begin{array}{l}\text { Winston et al., } \\
2016\end{array}$ \\
\hline & $\begin{array}{l}\text { Discovery stage: AD } \\
(n=28) \text { aMCl }(n=25) \\
\text { CTRL }(n=29) \\
\text { Validation stage: AD } \\
(n=73) \text { aMCl }(n=71) \\
\text { CTRL }(n=72) \text { pre-AD } \\
(n=160) \text { CTRL } \\
(n=160)\end{array}$ & $\begin{array}{l}\text { Blood } \\
\text { nero-exosomal: } \\
\text { GAP43 Ng } \\
\text { SNAP25 } \\
\text { Synaptotagmin } \\
1\end{array}$ & $\begin{array}{l}\text { Discovery stage: AD } \downarrow \\
\text { vs. CTRL aMCl } \downarrow \text { vs. } \\
\text { CTRL aMCI } \uparrow \text { vs. AD } \\
\text { Validation stage: same } \\
\text { with discovery stage } \\
\text { The combination of } \\
\text { exosomal biomarkers } \\
\text { detected AD } 5 \text { to } \\
7 \text { years before cognitive } \\
\text { impairment } \\
\text { (AUC }=0.87-0.89 \text { ) }\end{array}$ & $\begin{array}{l}\text { Exosomal biomarker } \\
\text { levels were correlated } \\
\text { with those in CSF } \\
\left(R^{2}=0.54-0.70\right)\end{array}$ & $\begin{array}{l}\text { Longitudinal } \\
\text { and } \\
\text { retrospectively } \\
\text { study }\end{array}$ & $\begin{array}{l}\text { Antonell et al., } \\
2020 \text {; Jia et al., } \\
2020\end{array}$ \\
\hline & $\begin{array}{l}\mathrm{MCl} \text { or } \mathrm{ADD} \text { (in total } \\
n=59) \operatorname{CTRL}(n=29)\end{array}$ & $\begin{array}{l}\text { Paired } \\
\text { CSF/plasma } \\
\text { samples }\end{array}$ & $\begin{array}{l}\text { CSF: MCl } \uparrow \text { vs. CTRL } \\
A D \uparrow \text { vs. CTRL plasma: } \\
\text { AD vs. CTRL: no } \\
\text { change }\end{array}$ & $\begin{array}{l}\text { Positively correlated } \\
\text { with CSF tau; } \\
\text { Negatively correlated } \\
\text { with CSFA } \beta \text { 1-42/A } \beta \\
\text { 1-40; No correlation } \\
\text { between CSF and } \\
\text { plasma Ng. }\end{array}$ & $\begin{array}{l}\text { Case-control } \\
\text { study }\end{array}$ & $\begin{array}{l}\text { De Vos et al., } \\
2015 \text {; } \\
\text { Kvartsberg } \\
\text { et al., } 2015 \text { a }\end{array}$ \\
\hline
\end{tabular}

(Continued) 
TABLE 1 | Continued

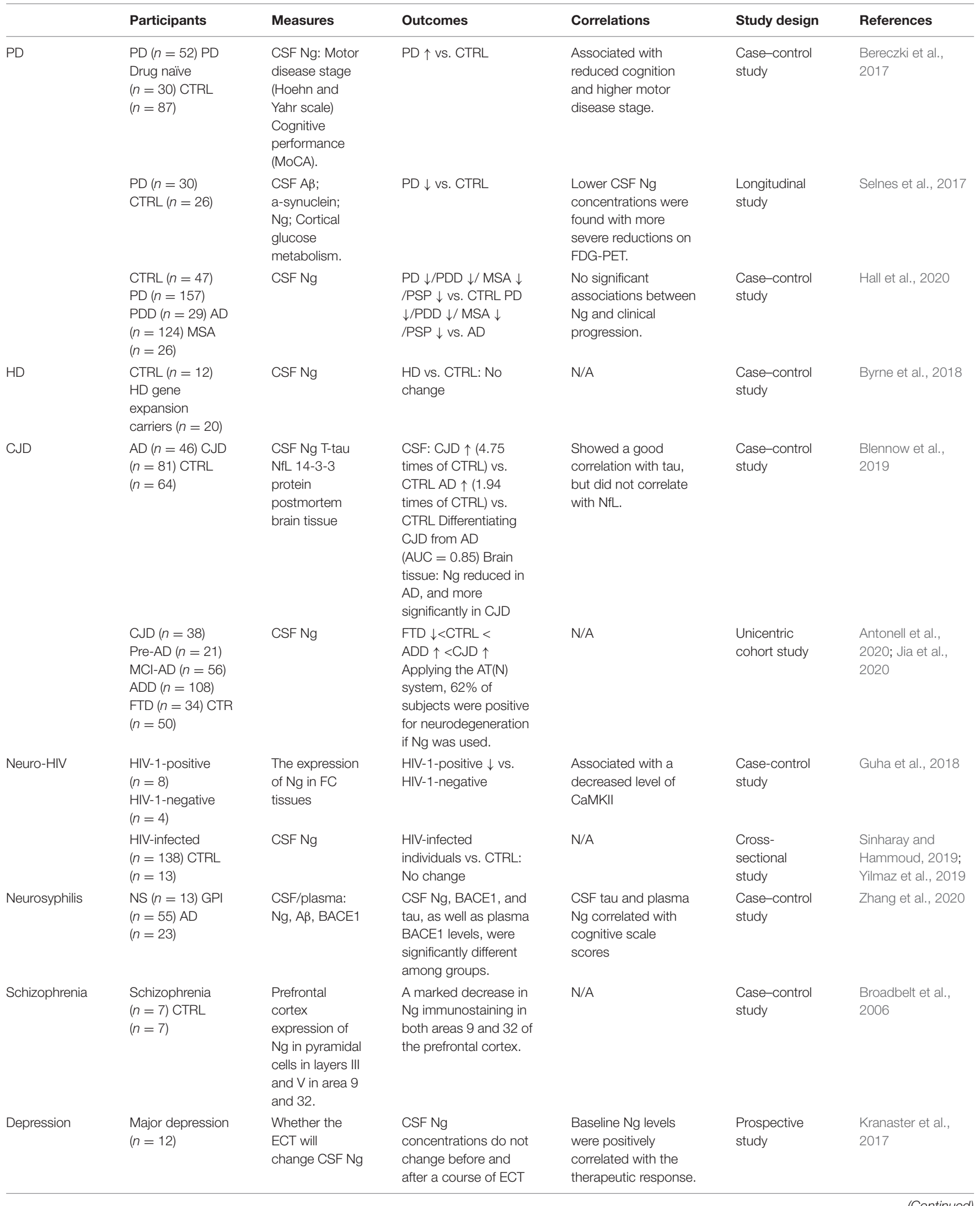


TABLE 1 | Continued

\begin{tabular}{|c|c|c|c|c|c|c|}
\hline & Participants & Measures & Outcomes & Correlations & Study design & References \\
\hline FEP & $\begin{array}{l}\text { FEP patients } \\
(n=40) \text { CTRL } \\
(n=20)\end{array}$ & CSF Ng & $\begin{array}{l}\text { FEP patients } \downarrow \text { vs. } \\
\text { CTRL }\end{array}$ & $\mathrm{N} / \mathrm{A}$ & Longitudinal study & Santillo et al., 2019 \\
\hline \multirow[t]{2}{*}{ TBI } & $\begin{array}{l}\text { TBI patients } \\
(n=76) \text { CTRL } \\
(n=150)\end{array}$ & Serum Ng & $\begin{array}{l}\text { TBI patients } \uparrow \text { vs. } \\
\text { CTRL with an ROC for } \\
\text { diagnosing TBI of } 0.72\end{array}$ & $\mathrm{~N} / \mathrm{A}$ & Case-control study & Yang et al., 2015 \\
\hline & $\begin{array}{l}\mathrm{CTRL}(n=328) \\
\operatorname{mTBI}(n=179)\end{array}$ & Serum Ng & $\begin{array}{l}\text { mTBI patients } \uparrow \text { vs. } \\
\text { CTRL }\end{array}$ & $\mathrm{N} / \mathrm{A}$ & $\begin{array}{l}\text { Prospective } \\
\text { observational study }\end{array}$ & $\begin{array}{l}\text { Peacock et al., } \\
2017\end{array}$ \\
\hline AIS & $\operatorname{AIS}(n=50)$ & $\begin{array}{l}\text { Paired } \\
\text { CSF/plasma Ng }\end{array}$ & $\begin{array}{l}\mathrm{Ng} \text { was elevated in } \\
\text { both CSF and plasma. }\end{array}$ & $\begin{array}{l}\text { Positively correlated } \\
\text { with infarct volume }\end{array}$ & Prospective study & De Vos et al., 2017 \\
\hline
\end{tabular}

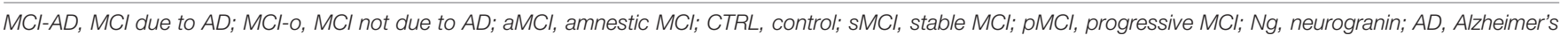

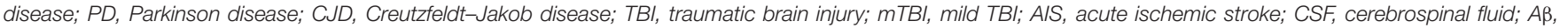

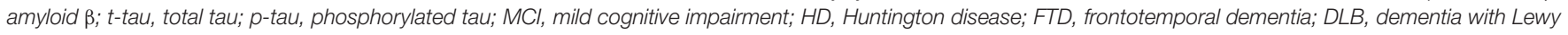

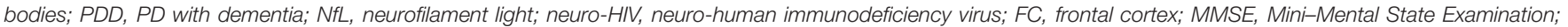

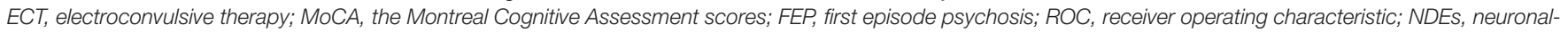

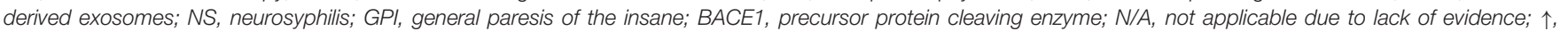
increased level; $\downarrow$, decreased level.

develop the diagnosis and prognosis for early symptomatic AD that is comparable with other CSF biomarkers of AD (Tarawneh et al., 2016). Importantly, CSF Ng enhances the comprehensive capacity of these biomarkers to predict future cognitive decline in the cognitively normal controls (Tarawneh et al., 2016).

Additionally, the data of $\mathrm{Ng}$ expression in postmortem brain tissues of $\mathrm{AD}$ demonstrated that the elevated CSF $\mathrm{Ng}$ levels are in accordance with the decreased $\mathrm{Ng}$ levels in the cerebral cortex and hippocampus (Blennow et al., 2019). $\mathrm{Ng}$ levels in brain tissues of $\mathrm{AD}$ do not differ between early and late Braak stages, indicating that synaptic loss is not only a late-stage pathological feature (Blennow et al., 2019). Therefore, CSF Ng is a promising biomarker for early diagnosis and progression prediction of $\mathrm{AD}$, which could be a useful complement to the panel of $\mathrm{AD}$ biomarkers currently.

For clinical applications, sample collection needs to be as accessible and reproducible as possible. However, no significant differences were found in plasma levels of $\mathrm{Ng}$ between $\mathrm{AD}$ patients and controls (De Vos et al., 2015), indicating the necessity of developing other kinds of Ng-related biomarkers from the blood. In that regard, a pilot study investigated the blood-derived $\mathrm{Ng}$ and revealed that the concentrations of $\mathrm{Ng}$ in the plasmatic NDEs are significantly lower in AD compared with the controls and correlate with the progression from MCI to $\mathrm{AD}$ (Winston et al., 2016). A recent meta-analysis uncovered that compared with the cognitively normal controls, the levels of plasmatic NDEs Ng in AD patients have an obvious decrease (Liu et al., 2020). Moreover, a recent study confirmed the difference in plasmatic NDEs $\mathrm{Ng}$ between $\mathrm{AD}$ patients and controls (Jia et al., 2020). Furthermore, the plasmatic exosomal levels of $\mathrm{Ng}$ are found to be correlated with CSF Ng levels. Also, the plasmatic exosomal $\mathrm{Ng}$ distinguishes $\mathrm{AD}$ with amnestic MCI and controls with the highest accuracy among all the plasmatic exosomal synaptic protein candidates, including growth-associated protein 43 , Ng, synaptosome-associated protein 25 , and synaptotagmin 1 (Jia et al., 2020).

The NIA-AA Research Framework, published in 2018, emphasized the necessity of a biological definition of $\mathrm{AD}$ and established the $\mathrm{A} / \mathrm{T} / \mathrm{N}$ ) biomarker classification system (Jack et al., 2018). In the framework, “A," “T” and “(N)" stand for $\mathrm{A} \beta$, tau, and neurodegeneration, respectively. It is generally recognized that " $N$ " includes the cellular injury, regional volume loss of the brain, and the destruction of system-level circuits (Jack et al., 2018). Taken together, as a postsynaptic protein, the current evidence suggests that $\mathrm{Ng}$ is a promising biomarker reflecting synaptic dysfunction in AD. The value of CSF Ng in the diagnosis and prediction of $\mathrm{AD}$ has been clarified, but the relationship between blood-derived $\mathrm{Ng}$ and $\mathrm{AD}$ still needs further study.

\section{Cerebrospinal Fluid Neurogranin in Parkinson Disease}

Characterized by the loss of nigrostriatal dopaminergic neurons, $\mathrm{PD}$ is the second most common primary ND of the CNS, whose major clinical manifestation is the development of movement disorder (Barker and Transeuro consortium, 2019). Synaptic dysfunction is an early change in $\mathrm{PD}$, which has been shown in a previous animal study (Yarnall et al., 2013). It proved that the neurons expressing $\mathrm{Ng}$ in the cortex degenerate in the late stage of PD (Yarnall et al., 2013). Besides, the levels of phosphorylated $\mathrm{Ng}$ are also lower in the superior temporal cortex in PD patients (Koob et al., 2014).

A study enrolled $52 \mathrm{PD}$ patients and $87 \mathrm{HCs}$, measured the CSF concentrations of $\mathrm{Ng}$, and explored the associations between $\mathrm{Ng}$ with motor symptoms (evaluated by Hoehn and Yahr scale) as well as cognitive symptoms (evaluated by the Montreal Cognitive Assessment scores) (Bereczki et al., 2017). It showed significant associations between increased concentrations of CSF $\mathrm{Ng}$ and cognitive impairment in the PD group, and CSF $\mathrm{Ng}$ is increased in $\mathrm{PD}$ patients in a disease-specific manner and associated with the severity of cognitive decline and motor disorder (Bereczki et al., 2017). Confusingly, a subsequent study showed the inconsistent results that enrolled 30 patients with mild-to-moderate PD and $26 \mathrm{HCs}$ and tested the correlation between hypometabolism, CSF A $\beta$, CSF Ng, and CSF $\alpha$-synuclein (Selnes et al., 2017). It showed that the CSF $\mathrm{Ng}$ levels are significantly lower in mild-to-moderate PD than those in controls 
and associated with CSF A $\beta$ levels, CSF $\alpha$-synuclein levels, and motor stage (Selnes et al., 2017). A prospective study showed that the Ng levels are significantly lower in $\mathrm{PD}, \mathrm{PD}$ with $\mathrm{MCI}$, and PDD) relative to AD dementia (Portelius et al., 2018). A recent study tested the CSF Ng in patients with PD, PDD, AD, and HCs and investigated the possible correlations between CSF Ng with cognitive and motor impairment (Hall et al., 2020). They found that $\mathrm{Ng}$ is decreased in patients with PD and PDD compared with the HCs and AD patients, respectively (Hall et al., 2020). Nevertheless, they did not find that $\mathrm{Ng}$ correlates with a motor disorder, cognitive impairment, longitudinal cognitive decline, or the progression to dementia in PD (Hall et al., 2020).

To sum up, the research on PD and $\mathrm{Ng}$ is booming currently, but the diagnostic value of Ng in CSF still needs to be further explored. More importantly, the correlation between blood $\mathrm{Ng}$ and $\mathrm{PD}$ remains unclear.

\section{Cerebrospinal Fluid Neurogranin in Huntington Disease}

As an autosomal dominant inheritance disease, HD is devastating to patients and their families, which is caused by an expanded trinucleotide repeat of CAG in the gene of huntingtin (Bates et al., 2015). There is evidence that synaptic dysfunction is a critical feature in HD pathogenesis (Smith et al., 2005; Sepers and Raymond, 2014). The whole-brain gene expression study in postmortem HD patient brains proved that the NRGN is one of the most robustly downregulated genes in HD caudate compared with the controls (Hodges et al., 2006; Runne et al., 2007). However, Byrne et al. (2018) quantified Ng and triggering receptor expressed on myeloid cells-2 in CSF samples from HD mutation carriers and controls and found that CSF Ng levels do not significantly differ between HD and HCs (Byrne et al., 2018). In addition, it did not find the significant associations between CSF Ng levels and the disease burden score, total functional capacity, or motor score (Byrne et al., 2018).

In a word, Ng-related research in HD is still far behind that of $\mathrm{AD}$ and PD. This may attribute to the type and characteristics of the disease or the limitation of the current testing methods of $\mathrm{Ng}$.

\section{Cerebrospinal Fluid Neurogranin in Creutzfeldt-Jakob Disease}

Creutzfeldt-Jakob disease is a rapidly progressive and fatal neurodegenerative disease that is caused by misfolded, transmissible proteinaceous infectious particles (Uttley et al., 2020). One fundamental characteristic of CJD is synaptic degeneration and disorganization, resulting in neuronal loss and spongiform changes (Blennow et al., 2019). Actually, over a $30 \%$ reduction of the certain synaptic index in the brain has been found in prion disease compared with the controls (Clinton et al., 1993).

Blennow et al. (2019) investigated CSF Ng, t-tau, neurofilament light, and 14-3-3 protein in CJD $(n=81)$, $\mathrm{AD}(n=46)$, and neurological controls (NCs, $n=64)$. The accuracy of $\mathrm{Ng}$ that differentiates the three groups and $\mathrm{Ng}$ expression in postmortem brain tissue was evaluated. They found that CJD has the highest levels of CSF Ng, which is helpful in the prediction of prognosis of CJD, is not influenced by age or sex, and is dependent on disease subtype (Blennow et al., 2019). In detail, CSF Ng is elevated in MM1/MV1 molecular subtypes compared with the VV2 subtype, which is in line with the severity of cortical pathological affectation (Blennow et al., 2019). However, the authors did not consider CSF Ng as a specific marker of synaptic degeneration but rather a marker of neuronal damage (Blennow et al., 2019). A recent study had a unicentric cohort of 353 participants, including HC subjects, $\mathrm{AD}$, frontotemporal dementia (FTD), and CJD (Antonell et al., 2020). They analyzed and compared the diagnostic accuracy and differentiating capacity of four noncore biomarkers, which stand for the distinct aspects of the neurodegeneration process (Antonell et al., 2020). The rank of CSF Ng concentrations from lower to higher is FTD $<\mathrm{HC}<\mathrm{AD}<\mathrm{CJD}$, which is in concordance with previously published data. Comparing their capacity in differentiating among neurodegenerative dementias, CSF Ng shows the significant differences across all three groups (AD, FTD, and CJD) (Antonell et al., 2020).

At present, the relation of $\mathrm{Ng}$ and CJD is still scatteredly reported, in which CSF Ng has been evaluated for diagnosis and differential diagnosis, and the results are relatively consistent, suggesting that CSF Ng has the potential to be a CJD biomarker.

\section{Cerebrospinal Fluid Neurogranin in Other Neurodegenerative Disorders}

In addition to the $\mathrm{AD}, \mathrm{PD}$, and $\mathrm{HD}$, some scattered studies about CSF Ng in other NDs, including FTD, DLB, progressive supranuclear palsy (PSP), and multiple system atrophy (MSA), have been published so far (Wellington et al., 2016; Portelius et al., 2018). An optimized immunoassay was introduced to analyze CSF $\mathrm{Ng}$ in a retrospective cohort, which showed FTD does not have significantly elevated CSF Ng concentrations compared with controls (Wellington et al., 2016). Of note, CSF Ng concentrations are slightly higher in speech variant frontotemporal dementia compared with behavioral variant frontotemporal dementia (Wellington et al., 2016). A study investigated CSF levels of $\mathrm{Ng}$ and other two synaptic proteins in FTD. CSF samples were analyzed in 66 patients in the FTD spectrum and 19 HCs. Patients were stratified as per their tauto-A $\beta 42$ ratio (tau/A $\beta 42)$ (Clarke et al., 2019). In detail, patients with a ratio of $>1$ were considered as undergoing the likely $\mathrm{AD}$ pathology ("AD biomarker" group $[n=18]$ ), and patients with a ratio $<1$ were considered as undergoing the likely FTD pathology ("FTD biomarker" group $[n=48]$ ) (Clarke et al., 2019). However, no CSF synaptic proteins showed a pathological abnormality in the "FTD biomarker" group, and the higher CSF concentrations of $\mathrm{Ng}$ appear to be more related to $\mathrm{AD}$ pathology (Clarke et al., 2019).

In a study in which a total of 129 postmortem human brain samples were analyzed in brain regional-specific manner, it found that $\mathrm{Ng}$ levels are reduced across the brain regions in all the three dementia groups (DLB, PDD, and AD) compared with the controls (Bereczki et al., 2016). The most significant changes reflecting synaptic dysfunction were found in DLB patients, followed by patients with PDD and AD (Bereczki et al., 2016). The authors suggested that the proposition that synaptic biomarkers predicting cognitive decline in $\mathrm{AD}$ is supposed 
to be extended to DLB (Bereczki et al., 2016). In contrast, another retrospective cohort study did not show the significant differences in CSF Ng concentrations between DLB and controls (Wellington et al., 2016).

\section{Cerebrospinal Fluid Neurogranin in Infectious Diseases of the Central Nervous System}

Infectious diseases of the CNS have a sizable effect on local health-care systems and economies (Vora et al., 2014). The change in mental status induced by the inflammation is a hallmark of neurotropic pathogen infections of the CNS (Klein et al., 2017). Pathogens, including bacteria, viruses, fungi, and parasites, can invade the brain parenchyma and give rise to the inflammation and/or the infection of both meningeal and parenchymal compartments, which lead to the dysfunction of neurons, glia cells, and the neural networks (Cain et al., 2019). On the basis of the published studies so far, we mainly summarize the relationship between $\mathrm{Ng}$ and the following two infectious diseases of the nervous system.

\section{Cerebrospinal Fluid Neurogranin in Neuro-Human Immunodeficiency Virus Infection}

Soon after transmission, HIV can be detected in the CSF in most patients (Valcour et al., 2012). The antiretroviral therapy has decreased the rates of mortality and morbidity in HIVpositive $\left(\mathrm{HIV}^{+}\right)$patients and has decreased the incidence of HIV-associated dementia, which is the most severe stage of neuro-HIV (Sinharay and Hammoud, 2019). Synaptic disruption is crucial in the mechanisms of cognitive impairment in HIV1-infected patients (Everall et al., 1999; Green et al., 2019). Compared with neuronal apoptosis and HIV-encephalitis, the dendritic injury due to HIV-1 infection is more closely related to cognitive impairments among HIV-associated neurocognitive disorder (HAND) patients (Everall et al., 1999). Guha et al. (2018) compared the expression of $\mathrm{Ng}$ in the frontal cortex (FC) between HIV-1-positive subjects with and without HAND and the controls (Guha et al., 2018). The study found that the expression levels of $\mathrm{Ng}$ are reduced significantly in FC of HANDpositive patients in contrast with the uninfected individuals. Yet, a recent cross-sectional study showed that CSF Ng concentrations are in the same range for all the groups of HIV-infected patients and uninfected controls (Yilmaz et al., 2019).

\section{Cerebrospinal Fluid Neurogranin in Neurosyphilis}

NS, the clinical outcomes of nervous system infection of Treponema pallidum, can occur at any stage of syphilis (Ropper, 2019). NS is very insidious in the early stage, while its clinical manifestation in the late stage is very serious, which includes the general paresis and tabes dorsalis. Thus the early diagnosis and differential diagnosis are critical.

Intriguingly, patients with NS at a later stage general paresis of the insane (GPI) are found to have the brain pathology features of $\mathrm{AD}$ (Zhang et al., 2020). In a recent study, the levels of $\mathrm{Ng}$ and amyloid precursor protein cleaving enzyme (BACE1) in CSF and plasma, together with $\mathrm{A} \beta 40, \mathrm{~A} \beta 42$, and $\mathrm{t}$-tau in the CSF of AD patients $(n=23)$, GPI patients $(n=55)$, and NS patients
( $n=13$ ) were tested (Zhang et al., 2020). It found that the CSF concentrations of $\mathrm{Ng}, \mathrm{BACE} 1$, and tau and the plasma BACE1 levels significantly differ among all the groups (Zhang et al., 2020). Pooling data from GPI and NS patients, both CSF tau and plasma Ng levels, are associated with cognitive scale score. These findings indicate the potential of diagnosis, differential diagnosis, and assessment of the severity of NS (Zhang et al., 2020). However, there are a few other reports, and further research is needed.

\section{Cerebrospinal Fluid Neurogranin in Mental Disorders}

Millions of people experience mental disorders, such as schizophrenia and depression. These mental diseases are characterized by a combination of abnormal thoughts, emotions, behaviors, and perceptions (Quintero et al., 2019). Given the multifactorial complexity of these disorders, the biomarkers are supposed to assist in the early diagnosis, monitoring, and treatment selection. As a severe and complex mental disorder, schizophrenia has a lifetime prevalence of $\sim 1 \%$, constituting $\sim 1 \%$ of the global burden of the disease (Lora et al., 2012). A genome-wide association study identified a relationship between schizophrenia and the single nucleotide polymorphism of rs12807809 in the NRGN (Stefansson et al., 2009). In recent years, several reports attempted to reveal the association between rs12807809 polymorphism and schizophrenia among different populations, but the results were controversial (Li et al., 2010; Sudesh et al., 2017). A recent meta-analysis aiming to integrate the present studies on the 12807809 polymorphism showed a statistically significant association between schizophrenia and rs12807809 polymorphism in the overall population in the allelic model (odds ratio $=1.10,95 \%$ confidence interval $1.04-$ 1.17). Nevertheless, the subgroup analysis revealed that a similar association only exists in Caucasians but not in Asians (Jin et al., 2019). A study of postmortem brain tissues showed a significant decrease in $\mathrm{Ng}$ immunostaining in both areas 9 and 32 of the prefrontal cortex (PFC) in schizophrenia compared with controls (Broadbelt et al., 2006).

In an animal study, transgenic mice overexpressing $\mathrm{Ng}$ in the PFC show the enhanced local plasticity and increased rate of extinction learning among different behavioral tasks, suggesting that $\mathrm{Ng}$ signaling in the PFC may be a specific therapeutic target for the treatment of disorders that are characterized by impaired extinction of fearful stimuli, e.g., post-traumatic stress disorder, or of reward-associated stimuli, e.g., drug addiction (Zhong et al., 2015). Electroconvulsive therapy (ECT) is a wildly used treatment for severe depression, which is considered to facilitate the neurogenesis and neural plasticity (Rotheneichner et al., 2014). A study investigated the changes of CSF $\mathrm{Ng}$ in response to ECT treatment in patients with depression and found that the mean CSF Ng levels do not alter within a course of ECT, but the low baseline $\mathrm{Ng}$ levels in the patients with major depression are positively associated with the degree of therapeutic response (Kranaster et al., 2017).

Further, a study examined CSF Ng in patients with firstepisode psychosis (FEP) and HCs. It showed that CSF Ng is 
lower in FEP patients compared with the controls, although it is not statistically significant. In the FEP group, the significant effects of antipsychotic treatment, which is correlated to the lower levels of CSF $\mathrm{Ng}$, suggest that CSF $\mathrm{Ng}$ is probably changed as a consequence of minimal exposure to the antipsychotic treatment (Santillo et al., 2019).

In fact, studies on the association between $\mathrm{Ng}$ genotypes and psychiatric disorders, particularly schizophrenia, have been carried out for many years. However, the research on the relationship between body fluids-based $\mathrm{Ng}$ and mental disorders is still at an early stage and is worth further exploration.

\section{Serum Neurogranin in Traumatic Brain Injury}

Traumatic brain injury is a significant medical problem worldwide, which may cause short- or long-term synaptic changes in the CNS, resulting in an increased risk for cognitive impairment later in life (Svirsky et al., 2020). Animal studies showed that TBI could cause significant changes in axonal structure, synaptic structure, dendritic morphology, and spine density as a result of diffuse axonal injury and synaptic loss (Gao et al., 2011; Park and Biederer, 2013). A study developed a sensitive $\mathrm{Ng}$ sandwich ELISA to measure $\mathrm{Ng}$ quantitatively in serum samples from both cohorts of acute TBI patients and non-TBI controls. It found that serum $\mathrm{Ng}$ levels in acute TBI patients are significantly higher than those in non-TBI controls, with a ROC of 0.72 for diagnosing TBI (Yang et al., 2015). An observational emergency department study of head-injured and control patients also reached the consistent conclusions that $\mathrm{Ng}$ is elevated within 2-6 h after injury (Peacock et al., 2017). A recent study aimed to explore the effect of TBI on $\mathrm{Ng}$ by detecting the protein expression at different time points after injury (Svirsky et al., 2020). Adult male rats were subjected to either CCI group or sham group, and the expression of $\mathrm{Ng}$ and postsynaptic density (PSD) 95 was measured by Western blotting in the cortex and hippocampus at $1,7,14$, and 28 days after injury. It found that the contralateral and ipsilateral hippocampus have a significant reduction in $\mathrm{Ng}$ levels at 1 day after CCI injury. Besides, the levels of $\mathrm{Ng}$ in the ipsilateral hippocampus are still significantly decreased at 7 and 14 days after CCI injury, whereas they recover to sham levels by 28 days. These results indicated that CCI lowers $\mathrm{Ng}$ expression in a temporal and regional specificity manner (Svirsky et al., 2020).

As a disease entity, TBI is also a risk factor for a variety of neurological diseases. Current studies suggest that $\mathrm{Ng}$ has potential in TBI diagnosis and disease progression. However, the lack of clinical research has limited the further transformation and application of $\mathrm{Ng}$.

\section{Cerebrospinal Fluid and Plasma Neurogranin in Acute Ischemic Stroke}

Globally, stroke (including ischemic stroke and hemorrhagic stroke) affects around 13.7 million individuals per year and is the second leading cause of death (Lindsay et al., 2019). Ischemic stroke caused by arterial occlusion is responsible for the majority of stroke cases (Campbell et al., 2019). After a stroke, a period of plasticity involving the neuronal genesis and synaptic modulation is essential to spontaneous recovery, which contains compensatory adaptation and real neurologic recovery (Felling and Song, 2015). A prospective study exploring $\mathrm{Ng}$ in paired CSF/plasma samples of AIS patients used both ELISA and singlemolecule array (Simoa) technology for Ng measurement (De Vos et al., 2017). It showed that plasma Ng levels are only associated with the volume of cerebral infarction. Likewise, the levels of CSF $\mathrm{Ng}$ are significantly higher in patients with an infarction volume $>5 \mathrm{ml}$ than those in patients with smaller infarction volume. However, neither the symptoms severity nor long-term outcomes are correlated with Ng in plasma or CSF (De Vos et al., 2017).

In addition to $\mathrm{AD}, \mathrm{AIS}$ is the only disease that has been studied to observe levels of CSF and blood $\mathrm{Ng}$ and their correlation. The discussed findings suggest the potential of blood $\mathrm{Ng}$ in reflecting brain tissue damage. However, whether the blood and CSF Ng have certain consistency is still an unavoidable issue for bloodbased Ng. Recent studies have found that some kind of enzymes have the capacity of cleaving $\mathrm{Ng}$ and yielding specific fragments (Becker et al., 2018), which could influence the accuracy of the current detection methods. Therefore, the development of novel detection approaches is an urgent part of $\mathrm{Ng}$ clinical research.

\section{DISCUSSION}

Considerable evidence proves that a synaptic dysfunction is an early event in the pathogenesis of many neurodegenerative diseases, particularly in the AD (DeKosky and Scheff, 1990; Masliah, 2001) and PD (Jellinger, 2012). As a postsynaptic protein, $\mathrm{Ng}$ has been recommended as a promising biomarker for synapse loss or dysfunction (Brinkmalm et al., 2019). A series of clinical studies have confirmed the rationality, validity, sensitivity, and specificity of CSF Ng in the diagnosis for both $\mathrm{AD}$ dementia and prodromal AD. Thus, CSF $\mathrm{Ng}$ has been included in the $\mathrm{A} / \mathrm{T} / \mathrm{N})$ research framework of the biological definition of $\mathrm{AD}$ as an essential indicator of neurodegeneration (Jack et al., 2018).

However, there are still many problems in the development of the application of $\mathrm{Ng}$ from bench to bedside. So far, no clear evidence proves that $\mathrm{Ng}$ is a disease-specific biomarker, as the change of function and structure of synapse is common in the pathogenesis of different kinds of CNS diseases, indicating that the current research reports are insufficient to uncover the profile and potential application values of $\mathrm{Ng}$ in clinical practice. Besides, the consistency of the present results about $\mathrm{Ng}$ and $\mathrm{AD}$ is acceptable, but the other findings need more interpretation, such as the association of $\mathrm{Ng}$ with PD (Selnes et al., 2017; Hall et al., 2020), neuro-HIV (Guha et al., 2018; Yilmaz et al., 2019), FTD (Byrne et al., 2018; Clarke et al., 2019), etc., which in part attributes to the current measuring methods lacking high accuracy in detecting the proteins of extremely low levels both in CSF and blood.

Given that the blood samples are more accessible than CSF samples, striving has been made for replacing CSF-based biomarkers with blood-based biomarkers, especially for the diagnosis of NDs such as $\mathrm{AD}$. For instance, the blood and CSF levels of neurofilament light (a promising biomarker for 
$\mathrm{AD}$ diagnosis) has been proved consistent (Fortea et al., 2018; Jack et al., 2018), indicating that it is potential to develop a blood-based, rapid, simple, portable, and easily accessible testing method for the $\mathrm{AD}$ screening in community populations. Frustratingly, only scattered studies have investigated blood $\mathrm{Ng}$ levels but failed to show a significant difference between $\mathrm{AD}$ patients and HCs. Also, no significant correlation between CSF and blood $\mathrm{Ng}$ was reported previously (De Vos et al., 2015). Besides, blood Ng has also been poorly studied in other neurodegenerative diseases. Given that the concentration of CNS biomarkers outside of the CNS is often extremely low, it is difficult to be conducted using conventional clinical assays.

Other important factors complicating the analysis include peripheral expression of $\mathrm{Ng}$, the endogenous antibodies interfering with the measured results, and the proteases influence the catabolism of $\mathrm{Ng}$ (Zetterberg and Burnham, 2019). Since the discovery of $\mathrm{Ng}$ in 1990 (Watson et al., 1990), there are, to our knowledge, very few studies investigating its metabolic profile. Mass spectrometry analyses suggested that $\mathrm{Ng}$ is catabolized into several short C-terminal peptides, which can be identified in CSF, and only minute amounts of full-length $\mathrm{Ng}$ is present in CSF. Furthermore, it showed that $\mathrm{Ng}$ in human plasma exists as several endogenous peptides via analyzing paired plasma and CSF samples from patients with $\mathrm{AD}$ and HCs. Among the endogenous $\mathrm{Ng}$ peptides detected, CSF Ng 48-76 shows the most pronounced increase in patients with $\mathrm{AD}$ compared with the controls. Importantly, $\mathrm{Ng} 48-76$ is also proved to be dominant in the brain tissues of $\mathrm{AD}$ patients. However, $\mathrm{Ng}$ 48-76 is not detected in plasma. These findings indicate that this particular peptide is probably brain-specific (Kvartsberg et al., 2015b). Conversely, four of the $\mathrm{Ng}$ peptides found only in plasma are not generated after incubation of full-length $\mathrm{Ng}$ in Ng-depleted plasma, indicating that some certain enzymes existing in plasma have the capacity of cleaving $\mathrm{Ng}$ at different sites (Kvartsberg et al., 2015b).

On the basis of current studies, $\mathrm{Ng}$ is expressed in the lung, spleen, bone marrow, and platelets, which may contribute to its high concentrations in blood. Due to the high plasma concentrations of $\mathrm{Ng}$ in normal individuals (Kvartsberg et al., $2015 b)$, the subtle alteration is probably not detected in blood in

\section{REFERENCES}

Antonell, A., Tort-Merino, A., Rios, J., Balasa, M., Borrego-Ecija, S., Auge, J. M., et al. (2020). Synaptic, axonal damage and inflammatory cerebrospinal fluid biomarkers in neurodegenerative dementias. Alzheimers Dement. 16, 262-272. doi: 10.1016/j.jalz.2019.09.001

Barker, R. A., and Transeuro consortium. (2019). Designing stem-cell-based dopamine cell replacement trials for Parkinson's disease. Nat. Med. 25, 10451053. doi: 10.1038/s41591-019-0507-2

Bates, G. P., Dorsey, R., Gusella, J. F., Hayden, M. R., Kay, C., Leavitt, B. R., et al. (2015). Huntington disease. Nat. Rev. Dis. Primers. 1:15005. doi: 10.1038/nrdp. 2015.5

Becker, B., Nazir, F. H., Brinkmalm, G., Camporesi, E., Kvartsberg, H., Portelius, E., et al. (2018). Alzheimer-associated cerebrospinal fluid fragments of neurogranin are generated by Calpain-1 and prolyl endopeptidase. Mol. Neurodegener. 13:47. doi: 10.1186/s13024-0180279-z case of chronic progressive neurodegeneration like AD. Besides, $\mathrm{Ng}$ is catabolized into several short C-terminal peptides; the levels of which vary in CSF and plasma, implying that the development of monoclonal anti-Ng antibodies-based testing methods is relatively difficult.

In summary, blood-based biomarkers are an important development direction in the diagnosis of neurological and mental diseases due to their many advantages compared with CSF based biomarkers. Currently, the transformation process of $\mathrm{Ng}$ from bench to bed has been developing rapidly in the NDs, especially in AD. In other kinds of diseases, such as PD and schizophrenia, it also has a very great potential value of transformation and application. As an essential synaptic component, $\mathrm{Ng}$ is a potential and promising biomarker to improve the diagnosis, prognosis and severity evaluation of the neurological and mental diseases in the future with the development of detection approaches and sample processing.

\section{AUTHOR CONTRIBUTIONS}

All authors listed have made a substantial, direct and intellectual contribution to the work, and approved it for publication.

\section{FUNDING}

This study was supported in part by the National Natural Science Foundation of China Fund (Grant No. 81601112), Sichuan Department of Science and Technology Fund (Grant No. 2018SZ0141), Top Project of Youth Incubation Program of Military Medical Science and Technology (Grant No. 19QNP065), and China's Post-doctoral Science Fund (Grant No. 2017M623357).

\section{ACKNOWLEDGMENTS}

We are deeply appreciative of the participants in this study, and thank all staff for their support and assistance.

Bereczki, E., Bogstedt, A., Hoglund, K., Tsitsi, P., Brodin, L., Ballard, C., et al. (2017). Synaptic proteins in CSF relate to Parkinson's disease stage markers. NPJ. Parkinsons. Dis. 3:7. doi: 10.1038/s41531-017-0008-2

Bereczki, E., Francis, P. T., Howlett, D., Pereira, J. B., Hoglund, K., Bogstedt, A., et al. (2016). Synaptic proteins predict cognitive decline in Alzheimer's disease and Lewy body dementia. Alzheimers Dement. 12, 1149-1158. doi: 10.1016/j. jalz.2016.04.005

Blennow, K., de Leon, M. J., and Zetterberg, H. (2006). Alzheimer's disease. Lancet 368, 387-403. doi: 10.1016/s0140-6736(06)69113-7

Blennow, K., Diaz-Lucena, D., Zetterberg, H., Villar-Pique, A., Karch, A., Vidal, E., et al. (2019). CSF neurogranin as a neuronal damage marker in CJD: a comparative study with AD. J. Neurol. Neurosurg. Psych. 90, 846-853. doi: 10.1136/jnnp-2018-320155

Brinkmalm, A., Portelius, E., Brinkmalm, G., Pannee, J., Dahlen, R., Gobom, J., et al. (2019). Fluid-based proteomics targeted on pathophysiological processes and pathologies in neurodegenerative diseases. J. Neurochem. 151, 417-434. doi: $10.1111 /$ jnc. 14594 
Broadbelt, K., Ramprasaud, A., and Jones, L. B. (2006). Evidence of altered neurogranin immunoreactivity in areas 9 and 32 of schizophrenic prefrontal cortex. Schizophr. Res. 87, 6-14. doi: 10.1016/j.schres.2006.04.028

Byrne, L. M., Rodrigues, F. B., Johnson, E. B., De Vita, E., Blennow, K., Scahill, R., et al. (2018). Cerebrospinal fluid neurogranin and TREM2 in Huntington's disease. Sci. Rep. 8:4260. doi: 10.1038/s41598-018-21788-x

Cain, M. D., Salimi, H., Diamond, M. S., and Klein, R. S. (2019). Mechanisms of Pathogen Invasion into the Central Nervous System. Neuron 103, 771-783. doi: 10.1016/j.neuron.2019.07.015

Campbell, B. C. V., De Silva, D. A., Macleod, M. R., Coutts, S. B., Schwamm, L. H., Davis, S. M., et al. (2019). Ischaemic stroke. Nat. Rev. Dis. Primers. 5:70. doi: 10.1038/s41572-019-0118-8

Cheriyan, V. T., Alfaidi, M., Jorgensen, A. N., Alam, M. A., Abdullah, C. S., Kolluru, G. K., et al. (2020). Neurogranin regulates eNOS function and endothelial activation. Redox. Biol. 34:101487. doi: 10.1016/j.redox.2020.101487

Clarke, M. T. M., Brinkmalm, A., Foiani, M. S., Woollacott, I. O. C., Heller, C., Heslegrave, A., et al. (2019). CSF synaptic protein concentrations are raised in those with atypical Alzheimer's disease but not frontotemporal dementia. Alzheimers Res. Ther. 11:105. doi: 10.1186/s13195-019-0564-2

Clinton, J., Forsyth, C., Royston, M. C., and Roberts, G. W. (1993). Synaptic degeneration is the primary neuropathological feature in prion disease: a preliminary study. NeuroReport. 4, 65-68. doi: 10.1097/00001756-19930100000017

De Vos, A., Bjerke, M., Brouns, R., De Roeck, N., Jacobs, D., Van den Abbeele, L., et al. (2017). Neurogranin and tau in cerebrospinal fluid and plasma of patients with acute ischemic stroke. BMC Neurol. 17:170. doi: 10.1186/s12883017-0945-8

De Vos, A., Jacobs, D., Struyfs, H., Fransen, E., Andersson, K., Portelius, E., et al. (2015). C-terminal neurogranin is increased in cerebrospinal fluid but unchanged in plasma in Alzheimer's disease. Alzheimers Dement. 11, 14611469. doi: 10.1016/j.jalz.2015.05.012

DeKosky, S. T., and Scheff, S. W. (1990). Synapse loss in frontal cortex biopsies in Alzheimer's disease: correlation with cognitive severity. Ann. Neurol. 27, 457-464. doi: 10.1002/ana.410270502

Diez-Guerra, F. J. (2010). Neurogranin, a link between calcium/calmodulin and protein kinase C signaling in synaptic plasticity. IUBMB Life. 62, 597-606. doi: 10.1002/iub.357

Dugger, B. N., and Dickson, D. W. (2017). Pathology of Neurodegenerative Diseases. Cold Spring Harb. Perspect. Biol. 9:a028035. doi: 10.1101/cshperspect. a028035

Everall, I. P., Heaton, R. K., Marcotte, T. D., Ellis, R. J., McCutchan, J. A., Atkinson, J. H., et al. (1999). Cortical synaptic density is reduced in mild to moderate human immunodeficiency virus neurocognitive disorder. Brain Pathol. 9, 209-217. doi: 10.1111/j.1750-3639.1999.tb00219.x

Felling, R. J., and Song, H. (2015). Epigenetic mechanisms of neuroplasticity and the implications for stroke recovery. Exper. Neurol. 268, 37-45. doi: 10.1016/j. expneurol.2014.09.017

Fortea, J., Carmona-Iragui, M., Benejam, B., Fernández, S., Videla, L., Barroeta, I., et al. (2018). Plasma and CSF biomarkers for the diagnosis of Alzheimer's disease in adults with Down syndrome: a cross-sectional study. Lancet Neurol. 17, 860-869. doi: 10.1016/s1474-4422(18)30285-0

Fyfe, I. (2015). Neurogranin in the CSF signals early Alzheimer disease and predicts disease progression. Nat. Rev. Neurol. 11, 609-609. doi: 10.1038/nrneurol. 2015.178

Gao, X., Deng, P., Xu, Z. C., and Chen, J. (2011). Moderate traumatic brain injury causes acute dendritic and synaptic degeneration in the hippocampal dentate gyrus. PLoS One. 6:e24566. doi: 10.1371/journal.pone.0024566

Garrido-Garcia, A., De Andres, R., Jimenez-Pompa, A., Soriano, P., Sanz-Fuentes, D., Martinez-Blanco, E., et al. (2019). Neurogranin Expression Is Regulated by Synaptic Activity and Promotes Synaptogenesis in Cultured Hippocampal Neurons. Mol. Neurobiol. 56, 7321-7337. doi: 10.1007/s12035-0191593-3

Glynne, R., Ghandour, G., Rayner, J., Mack, D. H., and Goodnow, C. C. (2000). B-lymphocyte quiescence, tolerance and activation as viewed by global gene expression profiling on microarrays. Immunol. Rev. 176, 216-246. doi: 10.1034/ j.1600-065x.2000.00614.x

Gnatenko, D. V., Dunn, J. J., McCorkle, S. R., Weissmann, D., Perrotta, P. L., and Bahou, W. F. (2003). Transcript profiling of human platelets using microarray and serial analysis of gene expression. Blood 101, 2285-2293. doi: 10.1182/ blood-2002-09-2797

Green, M. V., Raybuck, J. D., Zhang, X., Wu, M. M., and Thayer, S. A. (2019). Scaling Synapses in the Presence of HIV. Neurochem. Res. 44, 234-246. doi: 10.1007/s11064-018-2502-2

Guha, D., Wagner, M. C. E., and Ayyavoo, V. (2018). Human immunodeficiency virus type 1 (HIV-1)-mediated neuroinflammation dysregulates neurogranin and induces synaptodendritic injury. J. Neuroinflamm. 15:126. doi: 10.1186/ s12974-018-1160-2

Hall, S., Janelidze, S., Zetterberg, H., Brix, B., Mattsson, N., Surova, Y., et al. (2020). Cerebrospinal fluid levels of neurogranin in Parkinsonian disorders. Mov. Disord. 35, 513-518. doi: 10.1002/mds.27950

Hellwig, K., Kvartsberg, H., Portelius, E., Andreasson, U., Oberstein, T. J., Lewczuk, P., et al. (2015). Neurogranin and YKL-40: independent markers of synaptic degeneration and neuroinflammation in Alzheimer's disease. Alzheimers Res. Ther. 7:74. doi: 10.1186/s13195-015-0161-y

Hodges, A., Strand, A. D., Aragaki, A. K., Kuhn, A., Sengstag, T., Hughes, G., et al. (2006). Regional and cellular gene expression changes in human Huntington's disease brain. Hum. Mol. Genet. 15, 965-977. doi: 10.1093/hmg/ddl013

Jack, C. R. Jr., Bennett, D. A., Blennow, K., Carrillo, M. C., Dunn, B., et al. (2018). NIA-AA Research Framework: Toward a biological definition of Alzheimer's disease. Alzheimers Dement. 14, 535-562. doi: 10.1016/j.jalz.2018.02.018

Jellinger, K. A. (2012). Neuropathology of sporadic Parkinson's disease: evaluation and changes of concepts. Mov. Disord. 27, 8-30. doi: 10.1002/mds.23795

Jeon, S. G., Kang, M., Kim, Y. S., Kim, D. H., Nam, D. W., Song, E. J., et al. (2018). Intrahippocampal injection of a lentiviral vector expressing neurogranin enhances cognitive function in 5XFAD mice. Exp. Mol. Med. 50:e461. doi: 10.1038/emm.2017.302

Jia, L., Zhu, M., Kong, C., Pang, Y., Zhang, H., Qiu, Q., et al. (2020). Blood neuroexosomal synaptic proteins predict Alzheimer's disease at the asymptomatic stage. Alzheimer's \& Dement. 6:78. doi: 10.1002/alz.12166

Jin, L., An, Z., Xu, B., Mu, D., Fu, S., Hu, H., et al. (2019). The association between rs12807809 polymorphism in neurogranin gene and risk of schizophrenia: A meta-analysis. Medicine 98:e18518. doi: 10.1097/MD.0000000000018518

Kester, M. I., Teunissen, C. E., Crimmins, D. L., Herries, E. M., Ladenson, J. H., Scheltens, P., et al. (2015). Neurogranin as a Cerebrospinal Fluid Biomarker for Synaptic Loss in Symptomatic Alzheimer Disease. JAMA Neurol. 72, 12751280. doi: 10.1001/jamaneurol.2015.1867

Klein, R. S., Garber, C., and Howard, N. (2017). Infectious immunity in the central nervous system and brain function. Nat. Immunol. 18, 132-141. doi: 10.1038/ ni.3656

Koob, A. O., Shaked, G. M., Bender, A., Bisquertt, A., Rockenstein, E., and Masliah, E. (2014). Neurogranin binds alpha-synuclein in the human superior temporal cortex and interaction is decreased in Parkinson's disease. Brain Res. 1591, 102-110. doi: 10.1016/j.brainres.2014.10.013

Kovacs, G. G. (2016). Molecular Pathological Classification of Neurodegenerative Diseases: Turning towards Precision Medicine. Int. J. Mol. Sci. 17:189. doi: 10.3390/ijms17020189

Kovacs, G. G. (2017). Concepts and classification of neurodegenerative diseases. Handb. Clin. Neurol. 145, 301-307. doi: 10.1016/B978-0-12-802395-2. 00021-3

Kranaster, L., Blennow, K., Zetterberg, H., and Sartorius, A. (2017). Electroconvulsive therapy does not alter the synaptic protein neurogranin in the cerebrospinal fluid of patients with major depression. J. Neural. Transm. 124, 1641-1645. doi: 10.1007/s00702-017-1802-z

Kvartsberg, H., Duits, F. H., Ingelsson, M., Andreasen, N., Ohrfelt, A., Andersson, K., et al. (2015a). Cerebrospinal fluid levels of the synaptic protein neurogranin correlates with cognitive decline in prodromal Alzheimer's disease. Alzheimers Dement. 11, 1180-1190. doi: 10.1016/j.jalz.2014.10.009

Kvartsberg, H., Portelius, E., Andreasson, U., Brinkmalm, G., Hellwig, K., Lelental, N., et al. (2015b). Characterization of the postsynaptic protein neurogranin in paired cerebrospinal fluid and plasma samples from Alzheimer's disease patients and healthy controls. Alzheimer's Res. Ther. 7:40. doi: 10.1186/s13195015-0124-3

Li, T., Li, Z., Chen, P., Zhao, Q., Wang, T., Huang, K., et al. (2010). Common Variants in Major Histocompatibility Complex Region and TCF4 Gene Are Significantly Associated with Schizophrenia in Han Chinese. Biol. Psych. 68, 671-673. doi: 10.1016/j.biopsych.2010.06.014 
Lindsay, M. P., Norrving, B., Sacco, R. L., Brainin, M., Hacke, W., Martins, S., et al. (2019). World Stroke Organization (WSO): Global Stroke Fact Sheet 2019. Int. J. Str. 14, 806-817. doi: 10.1177/1747493019881353

Liu, W., Lin, H., He, X., Chen, L., Dai, Y., Jia, W., et al. (2020). Neurogranin as a cognitive biomarker in cerebrospinal fluid and blood exosomes for Alzheimer's disease and mild cognitive impairment. Transl. Psych. 10:125. doi: 10.1038/ s41398-020-0801-2

Lora, A., Kohn, R., Levav, I., McBain, R., Morris, J., and Saxena, S. (2012). Service availability and utilization and treatment gap for schizophrenic disorders: a survey in 50 low- and middle-income countries. Bull. World Health Organ. 90, 47-54. doi: 10.2471/BLT.11.089284

Martinez, de Arrieta, C., Perez Jurado, L., Bernal, J., and Coloma, A. (1997). Structure, organization, and chromosomal mapping of the human neurogranin gene (NRGN). Genomics 41, 243-249. doi: 10.1006/geno.1997.4622

Masliah, E. (2001). Recent advances in the understanding of the role of synaptic proteins in Alzheimer's Disease and other neurodegenerative disorders. J. Alzheimer's Dis. 3, 121-129. doi: 10.3233/jad-2001-3117

Masliah, E., Mallory, M., Alford, M., DeTeresa, R., Hansen, L. A., and McKeel, D. W. (2001). Altered expression of synaptic proteins occurs early during progression of Alzheimer's disease. Neurology 56, 127-129. doi: 10.1212/wnl. 56.1.127

Mavroudis, I. A., Petridis, F., Chatzikonstantinou, S., and Kazis, D. (2019). A metaanalysis on CSF neurogranin levels for the diagnosis of Alzheimer's disease and mild cognitive impairment. Aging Clin. Exp. Res. 28:31463927 doi: 10.1007/ s40520-019-01326-z

Mons, N., Enderlin, V., Jaffard, R., and Higueret, P. (2001). Selective age-related changes in the PKC-sensitive, calmodulin-binding protein, neurogranin, in the mouse brain. J. Neurochem. 79, 859-867. doi: 10.1046/j.1471-4159.2001. 00646.x doi: 10.1046/j.1471-4159.2001.00646.x

Pak, J. H., Huang, F. L., Li, J., Balschun, D., Reymann, K. G., Chiang, C., et al. (2000). Involvement of neurogranin in the modulation of calcium/calmodulindependent protein kinase II, synaptic plasticity, and spatial learning: a study with knockout mice. Proc. Natl. Acad. Sci. U S A. 97, 11232-11237. doi: 10. 1073/pnas.210184697

Park, K., and Biederer, T. (2013). Neuronal adhesion and synapse organization in recovery after brain injury. Fut. Neurol. 8, 555-567. doi: 10.2217/fnl.13.35

Peacock, W. F. T., Van Meter, T. E., Mirshahi, N., Ferber, K., Gerwien, R., Rao, V., et al. (2017). Derivation of a Three Biomarker Panel to Improve Diagnosis in Patients with Mild Traumatic Brain Injury. Front. Neurol. 8:641. doi: 10.3389/ fneur.2017.00641

Portelius, E., Olsson, B., Hoglund, K., Cullen, N. C., Kvartsberg, H., Andreasson, U., et al. (2018). Cerebrospinal fluid neurogranin concentration in neurodegeneration: relation to clinical phenotypes and neuropathology. Acta Neuropathol. 136, 363-376. doi: 10.1007/s00401-018-1851-x

Portelius, E., Zetterberg, H., Skillbäck, T., Törnqvist, U., Andreasson, U., Trojanowski, J. Q., et al. (2015). Cerebrospinal fluid neurogranin: relation to cognition and neurodegeneration in Alzheimer's disease. Brain 138, 3373-3385. doi: 10.1093/brain/awv267

Quintero, M., Stanisic, D., Cruz, G., Pontes, J. G. M., Costa, T., and Tasic, L. (2019). Metabolomic Biomarkers in Mental Disorders: Bipolar Disorder and Schizophrenia. Adv. Exp. Med. Biol. 1118, 271-293. doi: 10.1007/978-3-03005542-4_14

Rafii, M. S. (2016). Targeting tau protein in Alzheimer's disease. Lancet 388, 2842-2844. doi: 10.1016/S0140-6736(16)32107-9

Represa, A., Deloulme, J. C., Sensenbrenner, M., Ben-Ari, Y., and Baudier, J. (1990). Neurogranin: immunocytochemical localization of a brain-specific protein kinase C substrate. J. Neurosci. 10, 3782-3792. doi: 10.1523/jneurosci.10-1203782.1990

Ropper, A. H. (2019). Neurosyphilis. N. Engl. J. Med. 381, 1358-1363. doi: 10.1056/ NEJMra1906228

Rotheneichner, P., Lange, S., O'Sullivan, A., Marschallinger, J., Zaunmair, P., Geretsegger, C., et al. (2014). Hippocampal neurogenesis and antidepressive therapy: shocking relations. Neural. Plast. 2014:723915. doi: 10.1155/2014/ 723915

Runne, H., Kuhn, A., Wild, E. J., Pratyaksha, W., Kristiansen, M., Isaacs, J. D., et al. (2007). Analysis of potential transcriptomic biomarkers for Huntington's disease in peripheral blood. Proc. Natl. Acad. Sci. U S A. 104, 14424-14429. doi: 10.1073/pnas.0703652104
Santillo, A. F., Lundgren, S., Xu, C., Orhan, F., Fatouros-Bergman, H., Blennow, K., et al. (2019). Neurogranin as a potential synaptic marker in the cerebrospinal fluid of patients with a first episode psychosis. Schizophr. Res. 208, 490-492. doi: 10.1016/j.schres.2019.01.010

Scheff, S. W., Price, D. A., Schmitt, F. A., DeKosky, S. T., and Mufson, E. J. (2007). Synaptic alterations in CA1 in mild Alzheimer disease and mild cognitive impairment. Neurology 68, 1501-1508. doi: 10.1212/01.wnl.0000260698.46517. $8 \mathrm{f}$

Selnes, P., Stav, A. L., Johansen, K. K., Bjornerud, A., Coello, C., Auning, E., et al. (2017). Impaired synaptic function is linked to cognition in Parkinson's disease. Ann. Clin. Transl. Neurol. 4, 700-713. doi: 10.1002/acn3.446

Sepers, M. D., and Raymond, L. A. (2014). Mechanisms of synaptic dysfunction and excitotoxicity in Huntington's disease. Drug. Discov. Today. 19, 990-996. doi: 10.1016/j.drudis.2014.02.006

Sinharay, S., and Hammoud, D. A. (2019). Brain PET Imaging: Value for Understanding the Pathophysiology of HIV-associated Neurocognitive Disorder (HAND). Curr. HIV/AIDS Rep. 16, 66-75. doi: 10.1007/s11904-01900419-8

Smith, R., Brundin, P., and Li, J. Y. (2005). Synaptic dysfunction in Huntington's disease: a new perspective. Cell Mol. Life Sci. 62, 1901-1912. doi: 10.1007/ s00018-005-5084-5

Stefansson, H., Ophoff, R. A., Steinberg, S., Andreassen, O. A., Cichon, S., Rujescu, D., et al. (2009). Common variants conferring risk of schizophrenia. Nature 460, 744-747. doi: $10.1038 /$ nature 08186

Sudesh, R., Priyadarshini, T., Preeti, R., John, S., Thara, R., Mowry, B., et al. (2017). Minor allele C of rs12807809 polymorphism in NRGN contributes to the severity of psychosis in patients with Schizophrenia in South Indian population. Neurosci. Lett. 649, 107-111. doi: 10.1016/j.neulet.2017.04.008

Svirsky, S., Henchir, J., Li, Y., Ma, X., Carlson, S., and Dixon, C. E. (2020). Neurogranin Protein Expression Is Reduced after Controlled Cortical Impact in Rats. J. Neurotrauma. 37, 939-949. doi: 10.1089/neu.2019.6759

Tarawneh, R., D’Angelo, G., Crimmins, D., Herries, E., Griest, T., Fagan, A. M., et al. (2016). Diagnostic and Prognostic Utility of the Synaptic Marker Neurogranin in Alzheimer Disease. JAMA Neurol. 73, 561-71. doi: 10.1001/ jamaneurol.2016.0086

Uttley, L., Carroll, C., Wong, R., Hilton, D. A., and Stevenson, M. (2020). Creutzfeldt-Jakob disease: a systematic review of global incidence, prevalence, infectivity, and incubation. Lancet Infect. Dis. 20, e2-e10. doi: 10.1016/s14733099(19)30615-2

Valcour, V., Chalermchai, T., Sailasuta, N., Marovich, M., Lerdlum, S., Suttichom, D., et al. (2012). Central nervous system viral invasion and inflammation during acute HIV infection. J. Infect. Dis. 206, 275-282. doi: 10.1093/infdis/ jis 326

Vora, N. M., Holman, R. C., Mehal, J. M., Steiner, C. A., Blanton, J., and Sejvar, J. (2014). Burden of encephalitis-associated hospitalizations in the United States, 1998-2010. Neurology 82, 443-451. doi: 10.1212/WNL.00000000000 00086

Watson, J. B., Battenberg, E. F., Wong, K. K., Bloom, F. E., and Sutcliffe, J. G. (1990). Subtractive cDNA cloning of RC3, a rodent cortex-enriched mRNA encoding a novel 78 residue protein. J. Neurosci. Res. 26, 397-408. doi: 10.1002/ jnr.490260402

Wellington, H., Paterson, R. W., Portelius, E., Tornqvist, U., Magdalinou, N., Fox, N. C., et al. (2016). Increased CSF neurogranin concentration is specific to Alzheimer disease. Neurology 86, 829-835. doi: 10.1212/Wnl. 0000000000002423

Winston, C. N., Goetzl, E. J., Akers, J. C., Carter, B. S., Rockenstein, E. M., Galasko, D., et al. (2016). Prediction of conversion from mild cognitive impairment to dementia with neuronally derived blood exosome protein profile. Alzheimers Dement 3, 63-72. doi: 10.1016/j.dadm.2016.04.001

Yang, J., Korley, F. K., Dai, M., and Everett, A. D. (2015). Serum neurogranin measurement as a biomarker of acute traumatic brain injury. Clin. Biochem. 48, 843-848. doi: 10.1016/j.clinbiochem.2015.05.015

Yarnall, A. J., Rochester, L., and Burn, D. J. (2013). Mild cognitive impairment in Parkinson's disease. Age Ageing. 42, 567-576. doi: 10.1093/ageing/aft085

Yilmaz, A., Fuchs, D., Price, R. W., Spudich, S., Blennow, K., Zetterberg, H., et al. (2019). Cerebrospinal Fluid Concentrations of the Synaptic Marker Neurogranin in Neuro-HIV and Other Neurological Disorders. Curr. HIV/AIDS Rep. 16, 76-81. doi: 10.1007/s11904-019-00420-1 
Zetterberg, H., and Blennow, K. (2015). Neurogranin Levels in Cerebrospinal Fluid: A New Addition to the Alzheimer Disease Diagnostic Toolbox. JAMA Neurol. 72, 1237-1238. doi: 10.1001/jamaneurol.2015.2075

Zetterberg, H., and Burnham, S. C. (2019). Blood-based molecular biomarkers for Alzheimer's disease. Mol. Brain. 12:26. doi: 10.1186/s13041-019-0448-1

Zhang, M., Zhong, X., Shi, H., Vanmechelen, E., De Vos, A., Liu, S., et al. (2020). BACE1 and Other Alzheimer's-Related Biomarkers in Cerebrospinal Fluid and Plasma Distinguish Alzheimer's Disease Patients from Cognitively-Impaired Neurosyphilis Patients. J. Alzheimers Dis. 77(1), 313-322. doi: 10.3233/jad200362

Zhong, L., Brown, J., Kramer, A., Kaleka, K., Petersen, A., Krueger, J. N., et al. (2015). Increased prefrontal cortex neurogranin enhances plasticity and extinction learning. J. Neurosci. 35, 7503-7508. doi: 10.1523/JNEUROSCI. 0274- 15.2015
Zhong, L., Cherry, T., Bies, C. E., Florence, M. A., and Gerges, N. Z. (2009). Neurogranin enhances synaptic strength through its interaction with calmodulin. EMBO J. 28, 3027-3039. doi: 10.1038/emboj.2009.236

Conflict of Interest: The authors declare that the research was conducted in the absence of any commercial or financial relationships that could be construed as a potential conflict of interest.

Copyright (c) 2020 Xiang, Xin, Le and Yang. This is an open-access article distributed under the terms of the Creative Commons Attribution License (CC BY). The use, distribution or reproduction in other forums is permitted, provided the original author(s) and the copyright owner(s) are credited and that the original publication in this journal is cited, in accordance with accepted academic practice. No use, distribution or reproduction is permitted which does not comply with these terms. 